BMJ Open Sport \& Exercise Medicine

\title{
Return to elite-level sport after clavicle fractures
}

Jonah Hebert-Davies, Julie Agel

To cite: Hebert-Davies J, Agel J. Return to elite-level sport after clavicle fractures. BMJ Open Sport \& Exercise Medicine 2018;4:e000371. doi:10.1136/ bmjsem-2018-000371

Accepted 29 August 2018

\section{Check for updates}

C Author(s) (or their employer(s)) 2018. Re-use permitted under CC BY-NC. No commercial re-use. See rights and permissions. Published by BMJ.

Department of Orthopaedic Surgery and Sports Medicine, Harborview Medical Center Seattle, Washington, USA

Correspondence to Dr Jonah Hebert-Davies; jdavies@uw.edu

\section{ABSTRACT}

Objective To determine if return to sport following clavicle fracture occurs earlier in high-level sports than the current standard of care allows for.

Design Observational study retrospective review of $\mathrm{NHL}$ prospective data.

Setting The study was performed at a university orthopaedic surgery department.

Patients NHL player with clavicle fracture.

Assessment of independent variables The independent variable including time on injured reserve and type of treatment.

Main outcome measures The primary study outcome measure was successful return to NHL play.

Results 15 athletes were identified; 10 were treated operatively and 5 non-operatively. The average return to ice hockey was 10 weeks. If the one outlier is removed, the average is 9.1 weeks. There was one re-fracture in the non-operative group. The average time from injury to return to sport was 65 days in the operative group and 97.6 days in the non-operative group. Two patients were unable to return play during the same season.

Conclusions High-end athletes safely return to atrisk sports after clavicle fracture much sooner than the average seen with non-elite athletes. Additional study may demonstrate that return to activity can likely be accelerated without significantly increasing complications.

\section{INTRODUCTION}

Mainstream news articles set the tone for public expectations for return to unrestricted activity after injury. Professional athletes who have access to extensive rehabilitation and a monetary motive are often cleared to return to contact sports sooner than non-athlete manual workers.

An article in the New York Times reported on an athlete returning to NHL play after a clavicle fracture quicker than a regular patient would be cleared to resume an elitelevel contact sport ${ }^{1}$. This led us to investigate the time from injury to return to sport for professional athletes in a high-risk sport (ice hockey).

Most conventional postinjury protocols recommend 2-3 weeks of immobilisation followed by gentle physical therapy and strengthening exercises at 6 weeks postoperatively. $^{2}{ }^{3}$ Although other studies have

\section{What are the new findings}

We may be restricting athletes unnecessarily long from return to activity.

How might it impact on clinical practice in the near future

Athletes could return to activity sooner than the current standard of practice.

examined functional outcomes following operative treatment of clavicle fractures, few have specifically looked at return to sport. Ranaletta et al retrospectively reviewed 54 athletes, including 31 'competitive' athletes having undergone open reduction and internal fixation (ORIF) of the clavicle. Patients could return to sport once they had radiographic fracture union and full shoulder range of motion. The mean time to return to sport was 68 days (range 5-180). ${ }^{4}$ Almost all $(94 \%)$ patients returned to the same level of sport. They reported a $16 \%$ complication rate, including one non-union, one hardware failure and one subclavian compression. They concluded that operative fixation of clavicle fractures offered safe, early return to sport with few complications.

Looking at fractures sustained while playing in the NFL, Vora et al identified 17 fractures over a 17-year period with a 3.5-month time loss and Jack et al identified 17 operative clavicle fractures that returned at an average 211 days and 32 non-operative clavicle fractures that returned at an average 245 days. ${ }^{5-7}$

Our aim was to determine if the outcome of the accelerated return to unrestricted activity seen in the NHL is safe and thus non-elite athletes are potentially being unduly restricted from return to activity and could safely be given shorter restrictions. It is our hypothesis that return to sport and activity following clavicle fracture occurs earlier in high-level sports than the current standard of care allows for. We analysed high-level ice hockey players because they are particularly vulnerable from 
body checks, stick checks and falls. Using data from the NHL, we examined time to return to sport and re-fracture or re-injury rate following clavicle fractures.

\section{MATERIALS AND METHODS}

This is a retrospective study evaluating all clavicle fractures over a 7-year period among NHL players. Injuries were identified from a prospective database of all player injuries in the NHL. No player-identifiable information was released with the data set. The athlete's date of injury, treatment, return to play and complication or re-fracture were recorded. The treatment and timing of return to sport were determined by the treating medical team. Player days missed was calculated as the time between the last game preinjury to the first game played postinjury. Summary analysis was done using Excel 2016 from Microsoft.

\section{RESULTS}

Fifteen athletes were identified. Ten athletes were treated operatively and five were treated non-operatively. The average return to ice hockey was 75.6 days (11 weeks) with a range of 33-236 days. If the one outlier (236 days, greater than three times the $\mathrm{SD}$ ) is removed, the average falls to 64 days (9.1 weeks). There was one re-fracture in the non-operative group that ultimately underwent operative fixation. There were no complications in the operative group. The average time from injury to return to sport was 65 days in the operative group and 97.6 days in the non-operative group. Two patients were unable to return to play during the same season, including the patient with a re-fracture. For both of these players, timing of injury was not a factor in their inability to return during the same season.

\section{DISCUSSION}

Over the last decade, operative treatment of displaced mid-shaft clavicle fractures has increased dramatically. ${ }^{8}$ This is likely due to several studies showing a definite reduction in non-union rates with ORIF. ${ }^{239}$ While the evolution of clavicle fracture treatment has had a profound impact on patient-reported functional outcomes, ${ }^{10}$ the same cannot be said for accelerated return to normal activity. Most rehabilitation protocols call for a short period of immobilisation with a return to moderate activity by 60 days postinjury. ${ }^{9}$

The New York Times article referenced a player who returned to full-time professional hockey 7 weeks after surgery ${ }^{1}$. The data from our study showed players returning at an average of 12 weeks. When looking at the results, while removing the one outlier patient, return to play is almost identical to the series from Ranaletta et al ( 66 vs 68 days). Another study by Meisterling et al on high school football players showed similar results. They presented 29 players having undergone ORIF of midshaft clavicle fractures. Average time for return to sport was 83 days with $23 \%$ returning before 42 days. ${ }^{11}$ There were no complications associated with return to sport. This allows us to suppose that results from professional athletes, though they represent a unique population, can be applied to other selected high-demand patients. In contrast, a study of workman's compensation patients treated with ORIF for clavicle fracture showed an average return to work of 196 days. ${ }^{12}$ Although there are many other mitigating factors in these cases, it demonstrates a possibility for improvement.

The potential risk for further injury following early return to activity is real and should be considered. In our cohort, one patient sustained a re-fracture after returning to play. This is similar to other studies, ${ }^{34}$ and the risk should be factored into decision-making by both surgeons and patients.

\section{CONCLUSION}

Treatment of clavicle fractures has evolved over the past decade. Currently, most patients are able to return to manual work after fracture consolidation at average of 16 weeks. ${ }^{2}$ Our study results demonstrate that high-end athletes can safely return to at-risk sports much sooner than the average delays seen with non-athletes. This suggests that return to work for many patients can likely be accelerated without significantly increasing complications.

Acknowledgements Robby Sikka and Jeff Stotts, NHL Injury Database (www. instreetclothes.com).

Contributors Both authors contributed equally to the manuscript.

Funding The authors have not declared a specific grant for this research from any funding agency in the public, commercial or not-for-profit sectors.

Competing interests None declared.

Patient consent Not required.

Provenance and peer review Not commissioned; externally peer reviewed.

Open access This is an open access article distributed in accordance with the Creative Commons Attribution Non Commercial (CC BY-NC 4.0) license, which permits others to distribute, remix, adapt, build upon this work non-commercially, and license their derivative works on different terms, provided the original work is properly cited, appropriate credit is given, any changes made indicated, and the use is non-commercial. See: http://creativecommons.org/licenses/by-nc/4.0/

\section{REFERENCES}

1. Strauss B. Patrick Kkane's quick return and healthy scoring touch provide a salve for a city. NY Times, 2015: B14.

2. Canadian Orthopaedic Trauma Society. Nonoperative treatment compared with plate fixation of displaced midshaft clavicular fractures. A multicenter, randomized clinical trial. J Bone Joint Surg Am 2007;89:1-10.

3. Robinson CM, Goudie EB, Murray IR, et al. Open reduction and plate fixation versus nonoperative treatment for displaced midshaft clavicular fractures: a multicenter, randomized, controlled trial. $J$ Bone Joint Surg Am 2013;95:1576-84.

4. Ranalletta M, Rossi LA, Piuzzi NS, et al. Return to sports after plate fixation of displaced midshaft clavicular fractures in athletes. $A m \mathrm{~J}$ Sports Med 2015;43:565-9.

5. Vora D, Baker M, Pandarinath R. Impact of clavicle fractures on return to play and performance ratings in NFL. Clin J Sport Med 2017:1.

6. Jack RA, Sochacki KR, Navarro SM, et al. Performance and return to sport after nonoperative treatment of clavicle fractures in National Football League players. Orthopedics 2017;40:e836-e843.

7. Jack RA, Sochacki KR, Navarro SM, et al. Performance and return to sport after clavicle open reduction and internal fixation 
in National Football League players. Orthop J Sports Med 2017;5:232596711772067.

8. Navarro RA, Gelber JD, Harrast JJ, et al. Frequency and complications after operative fixation of clavicular fractures. $J$ Shoulder Elbow Surg 2016;25:e125-e129.

9. McKee RC, Whelan DB, Schemitsch EH, et al. Operative versus nonoperative care of displaced midshaft clavicular fractures: a meta-analysis of randomized clinical trials. J Bone Joint Surg Am 2012;94:675-84.
10. Naimark M, Dufka FL, Han R, et al. Plate fixation of midshaft clavicular fractures: patient-reported outcomes and hardwarerelated complications. J Shoulder Elbow Surg 2016;25:739-46.

11. Meisterling SW, Cain EL, Fleisig GS, et al. Return to athletic activity after plate fixation of displaced midshaft clavicle fractures. $\mathrm{Am} \mathrm{J}$ Sports Med 2013;41:2632-6.

12. Shields $E$, Thirukumaran $C$, Thorsness $R$, et al. Patient factors influencing return to work and cumulative financial claims after clavicle fractures in workers' compensation cases. J Shoulder Elbow Surg 2016;25:1115-21. 